\title{
MATERIALISMO HISTÓRICO-DIALÉTICO E PESQUISA EM FONTES: CONTRIBUIÇÕES PARA A HISTÓRIA DA EDUCAÇÃO
}

\author{
Leandro Turmena ${ }^{1}$
}

\section{RESUMO}

O objetivo deste artigo é discutir a pesquisa em fontes e o método científico Materialismo Histórico-Dialético. Tal temática se justifica pela necessidade de analisar as fontes numa pesquisa sobre história da educação, tendo por base um aporte teórico, ou seja, um método científico de investigação. Assumindo a característica de pesquisa bibliográfica, o texto está organizado em duas partes. Primeiramente, a discussão sobre o método do Materialismo Histórico-Dialético e a pesquisa em educação e, posteriormente, o estudo e apontamentos sobre pesquisa em fontes. Considera-se que as fontes de pesquisa devem ser analisadas na totalidade, estudadas a partir das conexões (mediações), evidenciando as contradições, dos aspectos gerais/universais e particulares/singulares.

Palavras-chave: Pesquisa; Materialismo Histórico-Dialético; Fontes; História da Educação.

\section{HISTORICAL AND DIALECTICAL MATERIALISM AND RESEARCH SOURCES: CONTRIBUTIONS TO THE HISTORY OF EDUCATION}

\begin{abstract}
The purpose of this article is to discuss the research sources and the Dialectical and Historical Materialism scientific method. This subject is justified by the necessity to analyze the sources in a research about the History of Education, based on a theoretical basis, a scientific method of investigation. Taking into account the bibliographic research, the article is organized into two parts: First, the discussion of the Dialectical and Historical Materialism Method, as well as the research in education; then, the study and research considerations on sources research. It is understood that research sources must be analyzed in its totality, studied from the connections (mediation), highlighting the contradictions of the general / universal and the specific/ singular aspects.

Keywords: Research. Historical and Dialectical Materialism. Sources. History of Education.
\end{abstract}

"A história só fornece orientação, e todo aquele que encarar o futuro sem ela não só é cego mas perigoso, principalmente na era da alta tecnologia" (Eric Hobsbawm, 1998, p. 64).

\section{Introdução}

O objetivo deste artigo é discutir a pesquisa em fontes e o método científico Materialismo Histórico-Dialético. Tal temática se justifica pela necessidade de analisar as fontes numa pesquisa em história da educação, tendo como base um aporte teórico e um 
método científico de investigação. Neste sentido, o texto está organizado em duas partes. Primeiramente, consiste na discussão sobre o método Materialismo Histórico-Dialético e a pesquisa em Educação, a partir dos estudos de Frigotto (2001), Kuenzer (1998), Marx (1983, 1987 e 1996), Marx e Engels (1986 e 2004) e Munhoz (2006). Posteriormente, propõe-se o estudo e apontamentos sobre pesquisa em fontes. Para isso, foram consultados os textos de Castanho (2010), Costa (2010), Lombardi (2004), Melo (2010), Miguel (2004), Nosella e Buffa (2009), Saviani (2004) e Toledo e Gimenez (2009).

\section{Materialismo Histórico-Dialético e pesquisa em educação}

Consideramos que para a realização de pesquisas com fontes, neste caso em específico, em história da educação, é necessário um suporte teórico e um método científico que subsidiem a análise do objeto de investigação, no intuito de analisar a sua essência ${ }^{2}$. De acordo com Costa (2010, p. 197), "sem atribuir juízo de valor, o importante a salientar é a necessidade, sempre, de que o historiador da educação ter um arcabouço teórico, um método científico que lhe permite ler a realidade para além de sua aparência”.

Nesse sentido, apresentaremos - de forma sucinta - neste tópico, o método científico Materialismo Histórico-Dialético, pois entendemos que o mesmo, a partir de algumas categorias de análise - principalmente a categoria da totalidade - contribui significativamente para a pesquisa com fontes em história da educação.

Contrapondo-se ao método dialético-idealista elaborado por Hegel, Marx adentrou no campo da História no intuito de entender as relações que movimentam a mesma e neste terreno, desenvolveu sua teoria científica conhecida como Materialismo Histórico-Dialético ou Materialismo Histórico. A dialética materialista concebe o movimento, possuindo por base a matéria. Para os idealistas, é o pensamento, a ideia que cria a realidade. $O$ espiritual, o absoluto, são forças que se movem por si mesmas e que movimentavam todo o universo. Já para Marx o movimento do pensamento é um reflexo do real $^{3}$, pois na medida em que é produto do cérebro humano e que o homem é, ele próprio, produto da história, o pensamento não poderia deixar de ser também um produto desta mesma história. A partir de Marx e Engels (1986, p. 20), "não é a consciência que determina a vida, mas sim a vida que determina a consciência".

Nessa perspectiva, segundo Marx (1987, p. 29-30), eis a tese do Materialismo Histórico-Dialético

[...] na produção social da própria vida, os homens contraem relações determinadas, necessárias e independentes de sua vontade, relações de produção estas que correspondem a uma etapa determinada de desenvolvimento das suas forças produtivas materiais. A totalidade destas relações de produção forma a estrutura econômica da sociedade, a base real sobre a qual se levanta uma superestrutura jurídica, e à qual correspondem formas sociais determinadas de consciência. $\mathrm{O}$ modo de produção da vida material condiciona o processo em geral de vida social, político e espiritual. Não é a consciência dos homens que determina o seu ser, mas, ao contrário, é o seu ser social que determina sua consciência.

O ponto de partida é a existência real do ser homem e mulher, "[...] partimos dos homens em sua atividade real, é a partir de seu processo de vida real que representamos 
também o desenvolvimento dos reflexos e das representações ideológicas desse processo vital" (MARX;ENGELS, 1986, p. 19). O que os indivíduos são depende, incondicionalmente, das condições materiais de como os mesmos produzem sua existência/subsistência. "É na vida real que começa, portanto, a ciência real, positiva, a análise da atividade prática, do processo, do desenvolvimento prático dos homens" (MARX;ENGELS, 1986, p. 20). E continua: “A primeira condição de toda a história humana é, naturalmente, a existência de seres humanos vivos. A primeira situação a constatar é, portanto, a constituição corporal desses indivíduos e as relações que ele gera entre eles e o restante da natureza" (MARX;ENGELS, 1986, p. 10). Portanto, "toda historiografia deve partir dessas bases naturais e de sua transformação pela ação dos homens, no curso da história" (MARX;ENGELS, 1986, p. 10).

Neste sentido, interessava a Marx explicar a base material da sociedade em que viviam em pleno século XIX. A ele importava saber qual era a base econômica que sustentava essa sociedade: quem produzia, como produzia, com que produzia, para quem produzia e assim por diante, numa perspectiva de transformação social. Foi visando a isso que Marx se lançou ao estudo da economia política, tomando como ponto de partida a escola inglesa, cujos expoentes máximos eram Adam Smith e David Ricardo.

Numa sociedade estruturada sob o modo de produção capitalista, as relações sociais são relações de classes, pois implicam relações de luta entre os proprietários dos meios de produção, a burguesia e os não-proprietários, o proletariado, os modernos operários, ou seja, a classe dos que vivem do próprio trabalho. Entretanto, na sociedade capitalista as relações econômicas de produção se dão entre os que compram e os que vendem a força de trabalho (mercadoria) o que se constitui na infraestrutura. "Na mesma proporção que se desenvolve a burguesia, [...] o capital desenvolve também o proletariado, a classe dos operários modernos, que vivem apenas na medida em que encontram trabalho e que só encontram trabalho na medida em que o seu trabalho aumente o capital" (MARX;ENGELS, 2004, p. 51).

Sobre esta base econômica (infraestrutura) se levanta segundo Marx, uma superestrutura jurídica e política onde atua o Estado (política, religião, cultura, educação). Dessa forma, as relações sociais de produção da existência são antagônicas. Há um jogo de relações de forças que se articulam ao nível da infra e da superestrutura, na busca da consolidação da hegemonia de uma classe (FRIGOTTO, 2001). A hegemonia na sociedade capitalista é exercida pela classe dominante ${ }^{4}$, a burguesia. "A hegemonia é a capacidade de direção cultural e ideológica que é apropriada por uma classe, exercida sobre o conjunto da sociedade civil, articulando seus interesses particulares com os das demais classes de modo que eles venham a se constituir em interesse geral" (CURY, 1995, p. 48).

Investigar a base econômica do modo de produção capitalista e sua superestrutura onde ambas se articulam dialeticamente, pela ótica materialista, é uma tarefa desafiadora. Remonta ao uso do Materialismo Histórico-Dialético de Marx, bem como as categorias que o engendram, que são imprescindíveis para desvendar a essência do real na perspectiva de transformação social sob a ótica de opção da classe trabalhadora, pelo fato de esta representar a contradição da sociedade capitalista.

A categoria da totalidade é a primeira expressa por Marx no Método da Economia Política ${ }^{5}$ onde se parte do real, do concreto, dando a visão de totalidade.

Numa perspectiva de totalidade, não é correto afirmar que, por exemplo, na sociedade, o particular econômico predomina sobre os aspectos sociais, políticos e educacionais. A sociedade é entendida como um todo, como um conjunto de determinações que se integram e minunciosamente se relacionam. 
Nesse sentido é que Marx conceitua o concreto como a síntese de múltiplas determinações, ou seja, a unidade do diverso. Dialeticamente, o concreto "aparece no pensamento como o processo da síntese, como resultado, não como ponto de partida, ainda que seja o ponto de partida efetivo e, portanto, o ponto de partida também da intuição e da representação" (MARX, 1996, p. 39-40).

A categoria da totalidade implica numa concepção de realidade enquanto um todo (que é composto pelas partes) em processo dinâmico de estruturação, em que há a articulação entre o todo e as partes, as partes e o todo e, entre as diversas partes deste todo. Segundo Kuenzer (1998, p.65) "cada fenômeno ao revelar a si mesmo e ao todo, deverá ser compreendido como um momento do todo, que ao mesmo tempo explicita e o esconde".

Buscando um novo conhecimento, uma nova compreensão da realidade e para se ter uma visão concreta do objeto é preciso a superação da visão da realidade na perspectiva fenomênica. Isso se dá através do movimento do pensamento que vai do abstrato ao concreto pela mediação do empírico. Ou seja, "através do efetivo movimento da teoria para a prática e desta para a teoria [...] buscando sua concretude" (KUENZER, 1998, p. 64). Esse movimento de práxis que, a partir do empírico, busca na teoria já produzida os meios para sua compreensão, tende a reconstruir e reformular esta teoria na sua relação com o objeto de investigação, demonstrando o conhecimento verdadeiro. A categoria da práxis na pesquisa educacional assume um papel intencional onde o conhecimento e as críticas estão a serviço da transformação da realidade anterior no plano do conhecimento e no plano histórico-social (FRIGOTTO, 2001).

Nesse processo de investigação da realidade, em sua totalidade e visando à sua transformação, é importante também levar em consideração as categorias de contradição e mediação. A primeira vai desvelar no movimento as contradições " [...] enquanto relação ativa de contrários em busca de superação, mesmo que conservando o que cada um tem de determinado: a incessante conversão de um no outro, e exclusão ativa" (LEFEBRE apud KUENZER, 1998, p. 65), dando continuidade ao movimento histórico.

Para o Materialismo Histórico-Dialético, o todo não é a simples junção das partes, mas é a sua junção/relação com as partes. Esta relação do todo com as partes e vice-versa se dá através da mediação. É obvio que para conhecer um determinado objeto se torna necessário fazer uma cisão no todo, isolando alguns fatos particulares. Contudo, esta cisão é apenas um recurso teórico/metodológico para delimitação e análise do problema a ser investigado. De acordo com Kuenzer (1998, p. 65), "no contexto do real nada é isolado; isolar os fatos significa privá-los de sentido e inviabilizar sua explicação, esvaziando-os de seu conteúdo"; por isso a importância necessária de se trabalhar na pesquisa com a categoria da mediação.

Nesse sentido, é possível estudar até as ínfimas relações entre o todo e as partes, o simples e o complexo, a universalidade da teoria e a singularidade dos fenômenos e viceversa, e desvendar o conjunto de relações que se estabelece para a superação da aparência (concreto sensível, caótico, abstrato, porque pouco se sabe dele) à essência (concreto pensado, porque dele se conhecem as múltiplas determinações, e também abstrato, mas abstrato, pois se constitui numa construção mental sobre a realidade, determinada por esta mesma realidade). (MUNHOZ, 2006).

Nesta perspectiva, para a análise das fontes coletadas numa pesquisa em história da educação, no intuito de entender seus determinantes reais e concretos, é preciso entender o movimento do geral para o particular, isto é, do macro para o micro e do simples para o complexo, num movimento dialético que leve em consideração a mediação entre o todo e as 
partes, as contradições inerentes; o concreto (as múltiplas determinações) que são responsáveis pela existência de um fenômeno e, aquilo que Munhoz (2006) chama de sobredeterminações, ou seja, aquelas determinações identificadas como mais diretamente responsáveis pela existência de um fenômeno como tal. Isto é, as ínfimas determinações. Para tanto é preciso ter presente o que Kuenzer (1998) chama de "categorias de conteúdo". Nesta perspectiva, o pesquisador coletará e organizará os dados, caracterizando, assim, num "movimento que vai do geral ao particular na exposição, e do particular ao geral na investigação e na exposição" (KUENZER, 1998, p. 66).

Importante destacar a distinção feita por Marx entre o método de investigação e de exposição. O pesquisador, na análise investigativa, deve recolher o concreto e o real em suas múltiplas determinações e dimensões; deve apreender o específico, o singular; as mediações das partes com a totalidade; as contradições gerais e as contradições inerentes ao objeto pesquisado. Desta forma, a exposição busca ordenar de forma lógica (dialética), racional e coerente, a apreensão que se fez da realidade estudada (FRIGOTTO, 2001).

Segundo Marx (1983, p. 20),

É sem dúvida necessário distinguir o método de exposição, formalmente, do método de pesquisa. A pesquisa tem que captar detalhadamente a matéria, analisar as suas várias formas de evolução e rastrear sua conexão íntima. Só depois de concluído este trabalho é que se pode expor adequadamente o movimento do real. Caso se consiga isso, e espelhada idealmente agora a vida da matéria, talvez possa parecer que se esteja tratando de uma construção a priori.

Em tese, não se defende a ideia de que a realidade, as fontes coletadas, devem se encaixar incondicionalmente no método; e sim o seu contrário, de que o método - que demonstra a opção teórico/metodológica assumida - tem o papel de dar validade explicativa a estas fontes e aos objetos das pesquisas, visando ao desvendamento do concreto.

\section{A pesquisa em fontes}

Antes da discussão referente à pesquisa em fontes, tema este que iremos abordar neste tópico, é importante destacar que o "fazer história" é distinto de "escrever sobre a história". "O primeiro é a história propriamente dita, o desenrolar dos fatos. O segundo é a historiografia, ou seja, o ato de se escrever a história" (COSTA, 2010, p. 195).

É do conhecimento de todos que o presente de hoje é o passado de amanhã e, que a memória procura salvar o passado para servir o presente e o futuro. Por isso, atualmente, o ato de escrever sobre a história traz consigo a questão das fontes. No entanto, concordando com Nosella e Buffa (2009), a leitura das fontes não é uma atividade fácil. Depende da ótica teórica e ética e da política do pesquisador.

Castanho (2010), ao considerar que o conceito sobre as fontes se disseminou a partir da escola metódica do século XIX, cuja ênfase circunscreve a obra de Leopold von Ranke que considera o documento (escrito), a fonte por excelência da história, ressalta que Ranke, em sentido amplo, pode ser considerado um positivista, o que também o torna merecedor das críticas feitas pela Escola dos Annales à escola tradicional de matriz positivista a partir de 1930. Segundo seus críticos, a história tradicional 
[...] só dá atenção aos documentos escritos, aos testemunhos voluntários (decretos, cartas, relatórios etc.), ao passo que os documentos não escritos, ou testemunhos involuntários (vestígios arqueológicos, séries estatísticas etc) informam igualmente sobre as atividades humanas (BOURDÉ E MARTIN apud CASTANHO, 2010, p. 67).

No entanto, mesmo na leitura dos Annales, feita pelos autores acima citados, o leque de fonte ainda é restrito. Atualmente tem-se um arsenal de fontes - sejam elas escritas, audiovisuais, sonoras, pictóricas, iconográficas, arquitetônicas, mobiliárias, orais, dentre outras - que podem ser usadas para pesquisas em História da educação.

Nota-se que o objetivo principal deste texto é o uso de um aporte teórico, ou seja, de um método científico - como já citado, assumimos neste trabalho o Materialismo HistóricoDialético - para o trato com as diferentes fontes de pesquisa.

$\mathrm{Na}$ perspectiva da história e historiografia da educação, o pesquisador, para tirar o máximo de proveito das fontes, deve se preocupar com a totalidade dos fatos que envolvem tais fontes. "Quanto mais claro estiver o contexto social, político, cultural, econômico, etc., mais proveitoso será o diálogo com os autores sociais da época que 'falam' por intermédio de nossas fontes" (COSTA, 2010, p. 196).

Nesse sentido, para a história e, para a história da educação, as fontes são construídas num determinado período histórico, ou seja, são produções humanas. Segundo Lombardi (2004, p 155),

as fontes resultam da ação histórica do homem e, mesmo que não tenham sido produzidas com a intencionalidade de registrar a sua vida e o seu mundo, acabam testemunhando o mundo dos homens em suas relações com outros homens e com o mundo circundante, a natureza, de forma que produza e reproduza a condições de existência e de vida.

No entanto, Saviani (2004) analisando o conceito de fonte, os sentidos da palavra e as relações com a historiografia da educação, nos alerta para não considerarmos as fontes como origem do fenômeno histórico.

As fontes estão na origem, constituem o ponto de partida, a base, o ponto de apoio da construção historiográfica que é a reconstrução, no plano do conhecimento, do objeto histórico estudado. Assim, as fontes históricas não são a fonte da história, ou seja, não é delas que brota e flui a história. Elas, enquanto registros, enquanto testemunhos dos atos históricos, são a fonte do nosso conhecimento histórico, isto é, é delas que brota, é nelas que se apoia o conhecimento que produzimos a respeito da história (SAVIANI, 2004, p. 05$06)$.

Essa questão evidencia o caráter de totalidade e as múltiplas determinações que abrangem uma fonte histórica na investigação de um determinado objeto e para a construção da historiografia. Neste sentido, é importante observar segundo o autor, o caráter de inesgotabilidade das fontes históricas. "Sempre que a elas retornamos, tendemos a descobrir novos elementos, novos significados, novas informações que nos tinham escapado por ocasião das incursões anteriores" (SAVIANI, 2004, p. 06). Assim, é importante que o pesquisador defina claramente o que deseja pesquisar, recortando/delimitando o objeto e buscando as 
fontes necessárias que ajudem a problematizar e reconstruir (no âmbito da abstração/do pensamento - concreto pensado) o objeto de investigação e as relações que o envolvem. Pois os objetos investigados só adquirem estatuto de fontes diante do historiador na medida em que este formule um problema de pesquisa e delimite os elementos em que serão buscadas as respostas às questões levantadas. Consequentemente, os objetos selecionados e as respostas alcançadas passam a constituir fontes para a produção do conhecimento histórico (SAVIANI, 2004).

Atualmente no Brasil, especificamente a partir da década de 1990, tem aumentado o número de pesquisas em educação de caráter historiográfico e, consequentemente, o levantamento de fontes para tais. De acordo com Miguel (2004), o crescimento da historiografia se deve às pesquisas inerentes aos programas de pós-graduação e a ações de docentes via grupos de pesquisas nas universidades. No entanto, tal produção historiográfica é subsidiada pelas fontes. Algumas fontes estão cuidadosamente preservadas, em arquivos. Outras o cuidado é precário, pois faltam verbas, força de trabalho especializada e local/ambiente apropriado para sua conservação.

Nesta perspectiva, Saviani (2004) chama atenção para a preservação dos materiais de que nos servimos, seja como pesquisadores, seja como educadores tendo em vista a importância destes para estudos futuros. Para tanto o autor propõem em caráter de urgência uma política de fontes para a história da educação brasileira.

Esta é uma discussão proposta também por Toledo e Gimenez (2009). Segundo eles,

a organização e disponibilização da memória coletiva [...] não recebem dos governantes a atenção merecida. Cabe então, ao pesquisador, individualmente, fazer o trabalho que deveria ser de uma política pública de construção e preservação da memória (documentada) nacional e da cultura (documentada) no Brasil (p. 119).

Tal cuidado para com a preservação das fontes se dá pelo fato de que elas são materiais preciosos para a construção da historiografia educacional através de pesquisas que cumpram sua função social de compreender as questões educacionais brasileiras e encontrar soluções para as mesmas.

'A ciência não deve significar apenas um prazer egoístico' dizia Marx. 'Os que têm a oportunidade de se consagrar aos estudos científicos deverão ser os primeiros a pôr seus conhecimentos a serviço da humanidade'. Uma de suas frases mais favoritas era: 'Trabalhar pela humanidade' (LAFARGUE, 2004, p. 138).

Segundo Miguel (2004), a relação que se estabelece entre pesquisador, objeto de pesquisa e fontes buscadas e trabalhadas, a interpretação do que elas informam tem uma função social muito clara:

compreender o modo como a educação formal, no caso do sistema escolar, conformou-se historicamente; discernir os elementos que a informaram, isto é, que lhe deram um determinado conteúdo e pensar formas atuais; contribuir para que ela cumpra seu papel social: o de ser uma educação de qualidade para todos os brasileiros (p. 113). 
No entanto, as fontes não "falam" por si só. É preciso ler "as linhas e entrelinhas" e não confiar cegamente nos documentos e fontes consultados. Elas só são passíveis de interpretação ao serem contextualizadas. De acordo com Toledo e Gimenez (2009, p. 116), “[...] um pesquisador deve se manter sempre alerta e questionar as fontes e documentos. [...] É necessário analisá-los estruturalmente e historicamente".

Isso acarreta ao pesquisador a necessidade de análises da totalidade referente ao contexto histórico que envolve o objeto de investigação, levando em consideração as mediações e as contradições inerentes. Pois, "a amplitude do olhar do pesquisador se dá ao levantar as fontes. Aí ele não identifica apenas objetos específicos, mas descobre outras questões sociais que demarcaram um período" (MIGUEL, 2004, p. 116).

Nesse processo, visando dar conta da totalidade que envolve o objeto de investigação é importante não recorrer a uma única fonte e sim, confrontar várias fontes que problematizem o objeto de investigação possibilitando sua explicação e análise. Todavia, mesmo considerando que "todos os tipos de fontes são válidas para o entendimento do mundo e da vida dos homens, tem-se que convir que o tipo de fonte a ser utilizado decorre, em grande medida, do objeto de investigação" (LOMBARDI, 2004, p. 157). Nem sempre se tornam necessárias todas as fontes. "Em função dos objetivos específicos da pesquisa é possível, e até desejável, privilegiar umas e não outras. [...] o privilegiamento de uma ou outra fonte determina o tipo de história" (NOSELLA;BUFFA, 2009, p. 63).

Importante para a pesquisa em história da educação, consideramos a explicação e distinção dada por Toledo e Gimenez (2009) em relação às fontes primárias e secundárias.

Segundo estes autores, as fontes primárias remetem diretamente à própria problematização da pesquisa. São,

[...] aquelas que foram produzidas numa relação direta com o tema estudado. [...], por exemplo, as obras de um autor estudado. Elas devem ser relacionadas ao tema e à temática de pesquisa. [...] os documentos produzidos no período pesquisado e que possuem relação direta com a pesquisa feita, sejam eles os próprios originais depositados em arquivos ou digitalizados (ou copiados) (p.110).

Segundo Costa (2010, p. 193), "uma pesquisa que não se utilize de fontes primárias corre o risco de não ser aceita pela comunidade acadêmica como de História da Educação".

Em relação às fontes secundárias consideram-se aqueles documentos que nos transmitem os fatos de maneira indireta.

São relatos feitos por pessoas que não vivenciaram diretamente os episódios relatados e que se baseiam em outras fontes orais ou documentais, por exemplo. Elas são preciosas fontes de informação e também fornecem bases para uma interpretação. Sua função é fornecer ao pesquisador um lastro de informações (datas e fatos), de compreensão de conceitos e também, de configuração do referencial teórico-metodológico da análise. Entre tantos materiais, podemos relacionar, nesta categoria, os dicionários especializados, as enciclopédias, dados estatísticos, legislações e outras fontes de referência (p. 110-111).

Considerando os aspectos indissociáveis para a realização de uma pesquisa histórica, é 
preciso, após o recorte/delimitação da temática de investigação, eleger as fontes primárias, relacionar às fontes secundárias e à literatura de apoio ${ }^{6}$ para nelas sustentar a interpretação (TOLEDO;GIMENEZ, 2009).

Outro aspecto a salientar é o que Costa (2010) considera como parâmetros para se estabelecer o diálogo interpretativo com as fontes: o contexto em que a fonte está inserida e a temporalidade e historicidade do pesquisador.

Os documentos não pretendem e nem respondem a perguntas futuras, ou seja, eles não estão lá para dialogar com o nosso presente. [...] as fontes expressam o seu contexto e não o nosso. Isso é importante para evitar deslocar-se a fonte para um palco diferente do seu, para que não cobremos do passado posicionamentos e concepções que são as nossas (COSTA, 2010, p. 199).

E continua,

Embora estudemos o passado para compreendê-lo, isso é feito em conexão com o presente. É por isso que as mesmas fontes lidas por épocas distintas suscitam análises diferentes: recortes, excertos, planos, personagens etc., são escolhidos e/ou realçados diferentemente por distintos períodos históricos e, mesmo dentro de um mesmo período histórico, distintas formas de inserção social conduziram a abordagens distintas (COSTA, 2010, p. 201).

Castanho (2010) contribui para nossa discussão afirmando que a teoria da história marxiana é uma reflexão sobre a realidade histórica concreta. "A premissa básica dessa teoria é que o caminho percorrido pela sociedade [...] deve ser detectado com base na análise da realidade social contemporânea do pesquisador" (p. 11).

Tais questões nos alertam para o fato de que para a análise de uma determinada fonte numa pesquisa em história da educação, o estudo do passado está em constante conexão com o presente e que, dependendo do objeto de pesquisa, pode haver distintas abordagens. Eis o fundamento da visão marxiana de que o contemporâneo - mesmo a sociedade não tendo superado os aspectos característicos da modernidade - é o mais desenvolvido, o mais complexo, do que em tempos passados.

As fontes, como material empírico de análise, revelam os fatos ou, vice-versa. Entendemos que a análise das fontes e dos fatos deve ser a partir de um referencial teórico que mostre o sentido global dos mesmos. Assim, buscamos a contribuição de Marx e Engels (1998) referente à observação/análise empírica dos fatos:

Eis, [...] os fatos: indivíduos determinados com atividade produtiva segundo um modo determinado entram em relações sociais e políticas determinadas. Em cada caso isolado, a observação empírica deve mostrar nos fatos, e sem nenhuma especulação, nem mistificação, a ligação entre a estrutura social e política e a produção (p. 18).

Como exemplo, podemos citar a pesquisa histórica de uma instituição de ensino superior. Esta instituição, independente dos fatos que instiguem a problematização e o interesse pela investigação, levarão a diversas fontes ${ }^{7}$ de pesquisa que servirão de base para 0 estudo da mesma. Tais fontes encaminharão procedimentos a partir de um referencial teórico para a explicação dos fatos que envolvem o surgimento da instituição investigada. Essas fontes 
também poderão instigar a outros fatos - e, consequentemente outras fontes - que a priori não foram hipoteticamente observados. No entanto, as diversas fontes selecionadas para o estudo de uma instituição de ensino deverão contemplar as múltiplas determinações dos aspectos específicos/gerais, singulares/universais que de forma alguma se anulam, mas sim, se relacionam e se complementam pois, segundo Castanho (2010), a história da educação só ganha legitimidade na medida em que se articula com a totalidade histórica.

[...] não obstante o caráter totalizante e unitário que possui, a história se oferece, no quefazer acadêmico, em múltiplas especializações. Estas não quebram a totalidade e a unidade da história. São simples tratamentos específicos de dimensões diversas da realidade social. Dessa maneira, são legítimas formas historiográficas as que tratam a questão populacional (história demográfica), da questão do poder (história política), da questão da produção, circulação e consumo de bens e serviços (história econômica), da questão simbólica (história cultural), da questão da formação humana (história da educação) e assim por diante. Essa legitimidade [...] depende da continua articulação entre o domínio específico tratado e a totalidade histórica (pp. 95-96).

Complementando com Sanfelice (2007), para a realização de pesquisas da identidade de instituições escolares, neste caso, a partir do exemplo acima, de ensino superior, o pesquisador deve se lançar nos aspectos micro e macro que envolvem o objeto de investigação.

As instituições não são recortes autônomos de uma realidade social, política, cultural, econômica e educacional. Por mais que se estude o interior de uma instituição, a explicação daquilo que se constata não está dada de forma imediata em si mesma. "Mesmo admitindo que as instituições adquiram uma identidade, esta é fruto dos laços de determinações externas a elas e, como já foi dito, 'acomodadas' dialeticamente no seu interior" (SANFELICE, 2007, p. 79).

Tomando o rumo conclusivo deste texto enfatizamos que o método de investigação Materialismo Histórico-Dialético investiga as íntimas conexões, evidenciando as contradições, entre a forma pela qual a sociedade produz sua existência material e a instituição escolar que cria.

Assim como uma determinada sociedade foi condição para a criação e o desenvolvimento de uma determinada instituição escolar, esta é condição de existência daquela, porque lhe molda suas relações de produção, sem esquecer, porém, que, na produção da escola, a sociedade opera de forma conflituosa, pois suas opostas classes sociais lutam, em opostos campos, em favor de escolas que atendam aos seus próprios interesses (NOSELLA; BUFFA, 2009, p. 80).

Acreditamos que o pesquisador que leve em consideração a totalidade de fontes (as diversas fontes que envolvem um objeto de pesquisa, feitos os devidos recortes de análise) e a totalidade que envolve as fontes (os aspectos econômicos, políticos, sociais, educacionais, 
culturais, etc. - do particular, singular, geral e universal), caminha com passos firmes para a explicação do movimento do real, ou seja, da instituição estudada.

\section{Considerações finais}

Após a realização do estudo concluímos que, para pesquisas em fontes - neste caso pesquisas em história da educação - partindo do Materialismo Histórico-Dialético, o fundamental é relacionar as mediações entre o particular/singular (os aspectos relacionados com o dado empírico) com o geral/universal (totalidade social), evidenciando as contradições.

Assim, entendemos que, assumindo o Materialismo Histórico-Dialético como método científico de análise, para o trato com as fontes em história da educação, é possível caminhar rumo ao entendimento do movimento do real. O que implica em explicitar as relações entre o empírico, o abstrato e o concreto. Considerando que o concreto é para Marx, concreto pensado.

\section{Referências}

CASTANHO, Sérgio. Teoria da história e história da educação: por uma história cultural não culturalista. 1 ed. Campinas/SP: Autores Associados, 2010.

COSTA, Célio juvenal. Fontes Jesuíticas e a educação brasileira. In: COSTA, C. J.; PEREIRA MELO, J. J; FABIANO, L. H. (Orgs.) Fontes e métodos em história da educação. Dourados: UFGD, 2010. p. 193-214).

CURY, Carlos Roberto Jamil. Educação e contradição: elementos metodológicos para uma teoria crítica do fenômeno educativo. 6 ed. São Paulo: Cortez, 1995

HOBSBAWM, Eric. Sobre história. São Paulo: Companhia das Letras, 1998.

FRIGOTTO, Gaudêncio. $\mathrm{O}$ enfoque da dialética materialista histórica na pesquisa educacional. In: FAZENDA, I. (Org.) Metodologia da pesquisa educacional. 7 ed. v.11. São Paulo: Cortez, 2001. p. 69-90.

KUENZER, Acácia Zeneida. Desafios teórico-metodológicos da relação trabalho-educação e o papel social da escola. In: FRIGOTTO, G. (Org.). Educação e crise do trabalho: perspectives de final de século. Petrópolis: Vozes, 1998. p.55-75.

LOMBARDI, José Claudinei. História e historiografia da educação: atentando para as Fontes. In: LOMBARDI, J. C.; NASCIMENTO, M. I. M (Orgs.) Fontes, historia e historiografía da educação. Campinas/SP: Autores Associados: HISTEDBR; Curitiba/PR: Pontificia Universidade Católica do Paraná (PUCPR); Palmas/PR: Centro Universitario Diocesano do Sudoeste do Paraná (UNICS); Ponta Grossa/PR: Universidade Estadual de Ponta Grossa (UEPG), 2004. p. 141-176.

MARX, Karl. "Pósfácio à 2 Edição de O capital". In: O capital. São Paulo: Abril Cultural, 1983.

MARX, Karl. Contribuição à Crítica da Economia Política. São Paulo: Martins Fontes, 1987. MARX, Karl. Introdução à Crítica da Economia Política. In: Os Pensadores. São Paulo: Nova Cultural, 1996.

MARX, Karl. O capital: extratos por Paul Lafargue. São Paulo: Conrad Editora do Brasil, 2004.

MARX, Karl; ENGELS, Friedrich. Manifesto do Partido Comunista. São Paulo: Martin Claret, 2004.

MARX, Karl; ENGELS, Friedrich. A ideologia alemã (Feuerbach). São Paulo: Hucitec, 1986. 
MARX, Karl; ENGELS, Friedrich. A ideologia alemã. São Paulo: Martins Fontes, 1998. MELO, José Joaquim Pereira. Fontes e métodos: sua importancia na descoberta das heranças educacionais. In: COSTA, C. J.; PEREIRA MELO, J. J; FABIANO, L. H. (Orgs.) Fontes $e$ métodos em história da educação. Dourados: UFGD, 2010. p. 193-214).

MIGUEL, Maria Elisabeth Blanck. Do levantamento de Fontes à construção da historiografía: uma tentativa de sistematização. In: LOMBARDI, J. C.; NASCIMENTO, M. I. M (Orgs.) Fontes, historia e historiografía da educação. Campinas/SP: Autores Associados: HISTEDBR; Curitiba/PR: Pontificia Universidade Católica do Paraná (PUCPR); Palmas/PR: Centro Universitario Diocesano do Sudoeste do Paraná (UNICS); Ponta Grossa/PR: Universidade Estadual de Ponta Grossa (UEPG), 2004. p. 111-120.

MUNHOZ, Divanir Eulália Naréssi. Entre a universalidade da teoría e a singularidade dos fenómenos: enfrentando o sesafio de conhcer a realidade. Emancipação, Ponta Grossa/PR, v.06, n. 01, p. 25-40. 2006.

NOSELLA, Paolo; BUFFA, Ester. Instituições escolares: por que e como pesquisar. Campinas/SO: Alínea, 2009.

SANFELICE, José Luis. História das instituições escolares. In: NASCIMENTO, M. I. M.; LOMBARDI, J. C. e SANDANO, W. (Orgs.). Instituições escolares no Brasil: conceito e reconstrução histórica. Campinas/SP: Autores Associados, 2007.

SAVIANI, Dermeval. Educação: do senso comum à consciencia filosófica. 14 ed. Campinas, SP: Autores Associados, 2002.

SAVIANI, Dermeval. Breves considerações sobre Fontes para a história da educação. In: LOMBARDI, J. C.; NASCIMENTO, M. I. M (Orgs.) Fontes, historia e historiografía da educação. Campinas/SP: Autores Associados: HISTEDBR; Curitiba/PR: Pontificia Universidade Católica do Paraná (PUCPR); Palmas/PR: Centro Universitario Diocesano do Sudoeste do Paraná (UNICS); Ponta Grossa/PR: Universidade Estadual de Ponta Grossa (UEPG), 2004. p. 03-12.

TOLEDO, Cesar de Alencar Arnaut de.; GIMENEZ, José Carlos. Educação e pesquisa: Fontes e documentos. In: CASIMIRO, A. P. B. S.; LOMBARDI, J.C; MAGALHÃES, L. D. R. (Orgs.) A pesquisa e a preservação de fontes para a educação, cultura e memoria. Campinas: Alínea, 2009, p. 109-125.

\footnotetext{
1 Graduado em Filosofia e Pedagogia. Mestre em Educação pela Universidade Estadual de Ponta Grossa UEPG, Doutorando em Educação na Universidade Estadual de Maringá - UEM e docente do Instituto Federal do Paraná - IFPR, Câmpus Palmas. Paraná, Brasil. E-mail: leandro.turmena @ifpr.edu.br

2 “(...) o fenômeno, ao mesmo tempo que revela (manifesta) a essência, a esconde. (...) captar a verdadeira concreticidade não é outra coisa senão captar a essência. Não se trata, porém, de algo subsistente em si e por si que esteja oculto por detrás da cortina dos fenômenos. A essência é um produto do modo pelo qual o homem produz sua própria existência. Quando o homem considera as manifestações de sua própria existência como algo desligado dela, ou seja, como algo independente do processo que as produziu, ele está vivendo no mundo da 'pseudo-concreticidade'. Ele toma como essência aquilo que é apenas fenômeno, isto é, aquilo que é apenas manifestação da essência" (SAVIANI, 2002, p. 13).

${ }^{3}$ Do ponto de vista do materialismo histórico dialético, o ideal não é senão o material traduzido e transposto para a cabeça do homem (MARX, 1983). Com isso, Marx indicou um ponto importante que evidencia a diferença do materialismo dialético, com o idealismo e também com o materialismo mecanicista (Feuerbach).

4 "Os pensamentos da classe dominante são também, em todas as épocas, os pensamentos dominantes; em outras palavras, a classe que é o poder material dominante numa determinada sociedade é também o poder espiritual
} 
dominante. a classe que dispõe dos meios da produção material dispõe também dos meios da produção intelectual, de tal modo que o pensamento daqueles aos quais são negados os meios de produção intelectual está submetido também à classe dominante. os pensamentos dominantes nada mais são do que a expressão ideal das relações materiais dominantes; eles são essas relações materiais dominantes consideradas sob forma de ideais, portanto a expressão das relações que fazem de uma classe a classe dominante; em outras palavras, são ideias de sua dominação. os indivíduos que constituem a classe dominante possuem, entre outras coisas, também uma consciência, e consequentemente pensam; na medida em que dominam como classe e determinam uma época histórica em toda a sua extensão, é evidente que esses indivíduos dominam em todos os sentidos e que têm uma posição dominante, entre outras coisas também como seres pensantes, como produtores de ideias, que regulamentam a produção e distribuição dos pensamentos de sua época; suas ideias são portanto as ideias dominantes de sua época" (MARX;ENGELS, 1986, p. 48-49).

5 "Ao abordar a questão do método na economia política (...) é bom reiterar: pela primeira e única vez em sua obra, Marx na verdade está tratando da metodologia não apenas na economia política, mas em toda a ciência histórica. (...) para o autor não há ciência senão a da história" (CASTANHO, 2010, p. 28).

${ }^{6}$ Segundo estes autores, este tipo de material é indispensável numa pesquisa histórica. "Ele permitirá ao pesquisador estabelecer o necessário diálogo com a produção acadêmica relativa ao tema que é pesquisado, principalmente, a mais recente e mais especializada. Esse material é encontrado na fase de revisão bibliográfica, etapa essencial de uma pesquisa que pretende se credenciar nos meios acadêmicos" (TOLEDO;GIMENEZ, 2009, p. 111).

${ }^{7}$ Fontes primárias e secundárias: "Bibliografia pertinente: livros, revistas, boletins, monografias, memórias, dissertações, teses, relatórios, folder, sites, etc.; Documentos do acervo da própria escola: atas, livros de matrícula, anuários, programas de disciplinas, fotografias, etc.; Jornais da época, que constituem fonte importante por notificarem acontecimentos que compõem a memória; Documentos da Câmara Municipal, dos arquivos ou museus e, também, de arquivos particulares; Mapas, plantas, perspectivas; Legislação pertinente; Produção de novas fontes como a aplicação de entrevistas e questionários aos diferentes agentes da escola e a conhecedores da história local (NOSELLA;BUFFA, 2009, pp. 62-63). 